Session 3525

\title{
SOLAR SPLASH AS A CAPSTONE DESIGN PROJECT
}

\author{
Kurt J. Colella \\ U. S. Coast Guard Academy \\ Derek T. Schade \\ USCGC FORWARD (WMEC-911) \\ Scott Aten \\ USCGC SPAR (WLB-403)
}

\section{Introduction}

The senior-level design project is the capstone experience for all graduating engineering students. Senior design is the culmination of the design integration process, where the student's past experiences with design are called upon to successfully complete a demanding team design task. Design is an important component of the engineering profession and an integral part of the development of U.S. Coast Guard engineers.

At the U. S. Coast Guard Academy, design is considered a developmental experience ${ }^{3}$. The USCGA design philosophy introduces design as a process during the freshman year, stresses open ended problem solving the sophomore year, and incorporates component and system design the junior year. The senior year capstone experience serves as a medium for the student to demonstrate learned design skills and is the culmination of the students' design education.

The Solar Splash international solar powered boat design competition has provided Coast Guard Academy engineering students with an outstanding forum to successfully accomplish a comprehensive team design task. The Academy's desired outcomes with regard to capstone engineering include designing, constructing and evaluating (within a reasonable budget) a finished-product engineering system within specified goals and constraints. This experience offers students the opportunity to exercise leadership through teamwork in solving a challenging, "real-life" problem. This experience also is a means of increasing the involvement of cadets in professional society activities, and serves to increase student interaction with other universities and Coast Guard and industry professionals.

This paper summarizes CGA's participation in the Solar Splash event as a one semester senior design experience in 1995 and 1996. It has become evident that USCGA can successfully 
compete in a prestigious event with both a limited budget and limited outside support while achieving educational and professional objectives. The keys to success in such an endeavor are highly motivated students and an energetic faculty. 


\section{Background}

Solar Splash is a solar powered boat competition sponsored by the Solar Energy Division of the American Society of Mechanical Engineers and is held in Milwaukee, Wisconsin in June (established in 1994 ). A solar powered boat capable of carrying one person in three different events; a maneuverability test, a two hour endurance race and a 300 meter sprint race, must be designed and built. The vessel's performance is documented in a professional-quality written report which is also judged. Additional points are awarded for design displays located in each team's work area during the competition.

The boat is limited to a length of 6 meters, a beam of 2.4 meters, and height of 1.5 meters. The solar energy output of the solar cells is limited to 480 Watts under "one sun" conditions. The solar/electric system output voltage cannot exceed 52 VDC. The stability of the vessel is limited to a heel angle not greater than 15 degrees using a heeling moment created by hanging a $10 \mathrm{~kg}$ mass over the side at the outer edge of the maximum beam location.

\section{Team Building}

The decision to undertake the Solar Splash design project at USCGA rested squarely on the students' shoulders. The project was attractive to the cadets because of its applicability to a seagoing service and its use of technology which is pertinent to present real-world problems.

The design team for the 1996 Solar Splash competition consisted of seven engineering students from the Mechanical Engineering Department and one faculty member as project advisor. The respectable design and performance of the 1995 design and the limited time for project completion provided the rationale for the 1996 Solar Splash design team to use the original hull. However, modifications to the internal components and slight hull alterations were envisioned by the 1996 design team at the outset. Proposed design modifications were categorized into three general areas: the drive train, hydrodynamics, and the solar/electric system. The design team formed three independent sub groups to adequately analyze, evaluate and implement proposed modifications in each of these areas.

The philosophy of the 1996 CGA Solar Splash design team was to conduct more extensive testing and analysis than was possible in 1995. Well documented performance data allowed the team to base technical decisions on engineering principles supported by demonstrated results. To this end, all subgroups designed and carried out both laboratory and waterborne subsystem testing, and followed up with a fully integrated test and evaluation plan for the entire vessel. The following presents an outline of the procedures and results of the 1996 Solar Splash design team's test plan, and the details of CGA's 1996 Splash entry.

\section{Hull Subgroup}

The hull design for USCGA's 1996 Solar Splash entry was, for the most part, preserved from the 1995 entry. The design is a trimaran-type vessel with a streamline main hull and pontoons for stability. The original reasons for implementing this concept included reduced resistance, adequate stability, ease of constructibility, sufficient internal volume to accommodate a propulsion system, and adequate deck area to support a series of solar cells (figure 1). 
The hull and pontoons used in the 1995 competition were designed using the naval architecture software, Macsurf, and constructed of $64 \mathrm{lb}$ polyurethane foam. Armed with the results of the 1995 competition, the hull subgroup from the 1996 team identified several areas of concern and possible improvement with regard to the stability and hydrodynamic performance of the vessel.

First, the stability of the 1995 design was considered excessive. Motivated by the possibility of reducing pontoon weight and wetted surface area, the '96 team conducted a detailed inclining experiment (in CGA's tow tank facility) to determine the minimum pontoon buoyancy required to meet competition stability requirements. The inclining experiment was conducted with the vessel in the endurance configuration. Experimental calculations indicated that pontoon displacement could be reduced by over $60 \%$ while maintaining adequate stability. As a result of this test, the primary focus of the hull subgroup was to make the pontoons smaller and reduce the spray generated during the sprint portion of the competition.

With the limited time and financial resources available, the group decided to build two sets of pontoons. Design work resulted in the development of a displacement type pontoon and a planing pontoon made from a set of water skis. In addition to the new pontoon designs, a new support mechanism, capable of being mounted at more than one longitudinal location on the vessel was deemed necessary for configuration flexibility and added strength. The resulting design allowed for rapid vertical adjustment and angular rotation (pitch direction) of the pontoons. This support design was the key to conducting useful parametric studies of the proposed pontoons in both the sprint and endurance configurations.

Another area of concern for the hull subgroup was the smoothness of the hull surface and the fairing in of existing hull imperfections. The hull was made of 0.040 " aluminum sheet riveted together. The rivets were fiberglassed over and the resultant form was somewhat "bumpy." The first item of business was to remove the old hull coating and fair in the hull with body filler at all needed locations, keeping in mind the consequences of adding more weight. The preparation of the hull surface to accept its new coating involved the work of all group members within a concentrated time period of 3 days. After extensive preparation, a glossy five coat epoxy system was applied on the primed surface.

It is noteworthy to mention that the group considered low friction Teflon-based coatings, but after significant interaction with technical representatives from several vendors, and examining actual company test data, the group concluded that claims of drag reduction with Teflon based products are in the area of adhesion rather than the physics involved with boundary layer development (i.e. hydrodynamic drag). Based on this research, the group decide that the increased cost and level of finesse required to apply the Teflon coatings was not worth the relative return in drag reduction.

The final area of concern for the hull subgroup was the rudder design. The surface area of the 1995 rudder was excessive (validated with calculation and experiment). The 1996 group decided to use two separate rudders. The endurance event required greater maneuverability and less torque on the rudder stock at reduced speeds. The sprint event called for a small, high strength design, capable of merely keeping the vessel on a straight-line course at higher speeds. The rudder strength in the sprint event was considered critical because of the plans of the 
propulsion subgroup to increase the thrust output from the drive train above a level which had already sheared off the 1995 rudder.

The rudder analysis yielded two designs. The endurance rudder was made from foam laminated in fiberglass with galvanized conduit being used for a stock. The new endurance rudder was a balanced spade design and had a surface area of $40 \mathrm{in}^{2}$ as compared to 105 in $^{2}$ from 1995. The new surface area and center of pressure location resulted from lift and drag calculations on a variety of different standard foil sections and an attempt to reduce required torque by altering the profile geometry. The sprint rudder consisted of a solid steel stock and a "flapped" blade with a surface area of $15 \mathrm{in}^{2}$.

\section{Propulsion Subgroup}

The focus of Coast Guard Academy's 1995 Solar Splash Team was to develop a functioning drive train capable of surviving the competition. The propulsion system used in 1995 consisted of a conventional propeller mounted on a solid steel shaft and supported by an external cutlass bearing and stern tube. A thrust plate and electric motor support served to transmit the force from the propeller to the hull and align the motor with the shaft. Torque from the motor was transmitted to the shaft using a simple chain and sprocket drive system.

The philosophy of the 1996 design team was to assess the performance of the 1995 system and implement design changes based on experimental results. Since the 1995 entry used a 24-volt power system in the sprint event, it was decided at the outset to step up the system voltage in the sprint to the maximum allowable of 36 volts. The primary focus areas for the propulsion subgroup were; (1) added thrust support to accommodate higher system voltage, (2) investigation of a more efficient method of transmitting motor torque to the shaft, and (3) a closer examination of propeller performance in both the sprint ( $8 \mathrm{HP}, 36$ volts) and endurance (1 HP, 24 volt) configurations.

In order to allow the propulsion subgroup to proceed somewhat autonomously from the other subgroups, a drive train test platform was designed and constructed during the fall of 1995 to isolate the drive train from the rest of the hull. The barge consisted of a "box-like" enclosure which housed the entire drive train support mechanism, the propulsion shaft and propeller, and associated data acquisition equipment. The barge was designed such that it could be easily launched and retrieved from CGA's circulating water channel facility (see figure 2). Since the barge was free-floating, thrust measurements using a mechanical spring scale mechanism were possible to evaluate the effectiveness of various configurations.

The first series of barge tests consisted of an evaluation of three separate propellers for both the sprint and endurance configurations. The propellers were chosen because they represented a reasonable variety of diameters and blade pitches available to fit within the space between the shaft and the hull. All propellers were tested in both the sprint and endurance configurations and thrust, system current and system voltage were recorded over a 30 second time interval (sprint) and a one-hour time interval (endurance). Endurance testing was limited to one hour because of battery discharge rates. Barge testing was limited to use of batteries only (rather than batteries in conjunction with solar arrays) because of the proximity of the water channel to quantifiable daytime sun conditions. 
Examination of data from the propeller testing resulted in the choice of two different propellers. For the sprint, the choice was based solely on the propeller which exhibited the greatest output thrust. The choice of an endurance propeller was based on a combination of thrust, battery discharge rate, and the ability to load the electric motor closest to its rated operating point (highest efficiency).

Barge testing also established the need to "beef up" the motor support and thrust plate assembly in the sprint configuration. To this end, alterations were made to the original support/thrust system which increased its weight by more than $20 \%$. As a result, the decision was made to construct a separate thrust/support system for the endurance configuration to reduce overall vessel weight during that portion of the competition.

The performance of the chain-sprocket drive system was also evaluated in the test barge. It was compared to a smoother and quieter tracked-belt system. Basic concerns of misalignment due to the greater torque and thrust in the sprint configuration yielded the decision to stay with the stronger, and more forgiving, chain/sprocket system. In the endurance configuration however, the performance of the belt drive system was clearly superior to the chain drive. Under similar test conditions, the belt drive system resulted in $10 \%$ more thrust and a quantifiable reduction in electrical energy consumption.

In general, the implementation of the propulsion test barge allowed the propulsion subgroup to make significant improvements to the drive train mechanism and informed choices as to the best components to be used under different operational circumstances. Even more importantly, the barge allowed the subgroup to proceed somewhat autonomously from the hull and solar/electric subgroups.

\section{Solar/Electric Subgroup}

The objectives of the solar/electric subgroup were to utilize the on-hand photovoltaic panels (donated by Siemens Solar) to investigate the "best" configuration for both shoreside battery charging and underway battery charging during the endurance event. The subgroup categorized their tasks into three areas: (1) information gathering, (2) panel verification studies, and (3) configuration testing.

The information gathering stage involved basic research concerning the theory of operation of photovoltaic panels, extensive interaction with technical representatives from Siemens, and a visit to the Coast Guard's Research and Development Center (Groton, CT) where research involving photovoltaic panel use on buoys is ongoing. One of the most valuable lessons learned from this research was that the most critical factor in experimental tests involving photovoltaic panels is the ability to reproduce and systematically vary test conditions which involve the sun's intensity. With this in mind, the solar/electric subgroup was able to obtain a pyranometer (sun intensity meter) from the Coast Guard Research and Development Center to assist with testing.

The purpose of the panel configuration study was to ensure that all panels (Siemens model M55) in use were operating properly and within the specifications of the manufacturer. Panel I-V curves were reconstructed by varying the panel load under various sun conditions. 
This simple investigation allowed the subgroup to overcome the anxiety associated with unfamiliar technology, and also conduct a "hands-on" evaluation of the panels.

Panel configuration testing involved a parametric investigation of the charging characteristics of two types of batteries (different amp-hour ratings). Testing variables included (1) the number of batteries to be charged, (2) the time to "fully" charge, (3) the solar panel configuration (i.e. number of panels and panel electrical arrangement), and (4) the state of the charge present in the batteries before testing. It was concluded early on in the testing that in order to evaluate the "state of charge" on a battery it is important to know its complete charging and discharging history. An additional study of the influence of shading on panel performance was carried out and resulted in design changes involving the lowering of the driver's seat and relocation of the vessel's identification placard.

Results of the panel testing verified that three panels connected in parallel recharged the sprint batteries most effectively. In the endurance configuration, two pairs ( 2 panels in series) of panels connected in parallel (total of eight panels) provided the "best" performance without exceeding competition power output guidelines.

\section{System Testing}

After approximately ten weeks of subsystem testing and significant subgroup interaction, the system was fully integrated and a test plan was developed to evaluate its performance. Time was set aside to make necessary changes based on test results. Waterborne testing was conducted on the Thames River in New London, Connecticut. Three two hour endurance runs (two were completed successfully) and ten sprint runs were conducted. Resulting changes included moving the pontoons forward in the sprint configuration to reduce spray, a complete overhaul (not redesign) of all steering system components, the installation of a battery operated bilge pump system, and a modification to the vinyl cover system for the cockpit of the boat. Several procedural changes in the method of launch/recovery and operation were also adopted as a result of this testing.

\section{Transport}

An integral part of competing in Milwaukee involved the transport of the vessel from Connecticut to Wisconsin, and the ability to maneuver the vessel to and from the launching area at the competition site. A salvageable 21' boat trailer was purchased in the Fall of 1995 for $\$ 250.00$. After completing weld repairs, sandblasting and repainting the frame, repacking the wheel bearings and installing operational tail lights, the trailer was outfitted with a plywood cradle designed and built to accommodate the boat. The trailer was also outfitted with toolboxes to enhance its use as a work platform. All members of the group participated in the refurbishment and modification of the trailer.

\section{Performance}

USCGA placed fourth overall in the 1996 Solar Splash competition (7th place in 1995). A transmission failure in the second round of the sprint event prevented an even stronger finish. The Coast Guard Academy won the technical report competition and also placed first in the "visual display" competition. The visual display consisted of an 8 minute digital video 
presentation summarizing the '96 design changes and a poster board layout of pictures and diagrams for each subsystem.

In two 2-hour endurance runs, the '96 entry traveled a total distance of 29.61 miles (19.25 miles traveled in 1995) for a fourth place finish in that event. In the sprint, the first heat time was 34.3 seconds (44.1 seconds in 1995) which was the 4th fastest time recorded in the '96

competition. Without a transmission support failure in the second heat, CGA would have placed 3rd in the final sprint heat.

Another aspect of CGA's '96 success was that the finished product came in "on time and under budget." The '96 team spent $\$ 2120.00$ on design improvements (under the $\$ 3000.00$ allotted) which brought the two year ('95 and '96) CGA Solar Splash investment to a total of $\$ 4590.00$.

\section{Summary}

The capstone design experience is a significant element of engineering education because it affords students the opportunity to apply theoretical knowledge to a practical interdisciplinary problem. Students learn a great deal about their modeling abilities and face the normal problem solving dilemmas which are associated with engineering practice when they build, operate and document the systems they design ${ }^{2}$.

Solar Splash is considered an outstanding forum to achieve educational goals and outcomes commensurate with a capstone-level design experience. Additionally, it serves as a significant leadership experience for students to function effectively as a member of a team that is charged with developing a solution to a complex problem. The project requires student interaction with faculty, technicians, industry consultants, vendors and Coast Guard field personnel. The Coast Guard Academy cadets and faculty have shown that with a limited time window (1 semester), modest financial commitment and minimal outside sponsorship (all constraints which mimic real-life limitations), "success" is certainly achievable.

The students summarized their experience in the following excerpts from their prizewinning technical report ${ }^{1}$ :

"All in all, the 1996 group has experienced engineering design first hand. We have experienced the feelings of frustration and joy that come with hard work. We have experienced the camaraderie of a cohesive group and the value of constructive disagreement. We have learned that with testing and evaluation comes the peace of mind necessary to make sound decisions. Finally, we have learned never to be premature in 'chalking up' successes and failures. The true measure of success or failure is realized at the competition."

"...In closing, the following is a list of frequent reminders that we, as a group, felt were significant during our design experience: 
1. Test everything as realistically as possible and don't overlook wear and tear when doing so.

2. Don't make premature decisions: ..think....analyze...evaluate...then decide.

3. Simplicity is a significant design criteria.

4. Team organization and decision making frequently causes more problems than the technical aspects of the project.

5. If it works perfectly the first time, it's probably not engineering."

\section{References}

1. Aten, S., M. Ennis, E. Kellog, M. Paradise, B. Riemer, B. Rosello, D. Schade, "Solar Splash '96 Design Project Report," First Place Winner of the Technical Report Competition at Solar Splash '96, 10 May 1996.

2. Dixon, G. W., "Leadership Development in Engineering," United States Coast Guard Academy Alumni Association Bulletin, February 1997.

3. Wilczynski, V., K. Colella, G. Dixon, K. Hiles, P. Knowles, P. Yin, "Integrating Design Across the Curriculum," Innovations in Mechanical Engineering Curricula for the 1990's, The 1996 Curriculum Innovation Awards, ASME, 1996.

\section{Biographical Information}

LCDR KURT COLELLA is an Assistant Professor of Mechanical Engineering at the U. S. Coast Guard Academy and served as faculty advisor to the USCGA '96 Solar Splash team. He is a graduate of the U. S. Coast Guard Academy (B.S.), Massachusetts Institute of Technology (M.S.) and The University of Connecticut (Ph.D.). Within engineering education, his work focuses on capstone design.

ENS DEREK T. SCHADE is a 1996 Mechanical Engineering graduate of the U. S. Coast Guard Academy. He is presently assigned aboard the U. S. Coast Guard Cutter FORWARD (WMEC-911), home ported in Portsmouth, Virginia, as an Engineer Officer in Training.

ENS SCOT ATEN is 1996 Mechanical Engineering graduate of the U. S. Coast Guard Academy. He is presently assigned aboard the U. S. Coast Guard Cutter SPAR (WLB-403) home ported in South Portland, Maine as a Deck Watch Officer. 


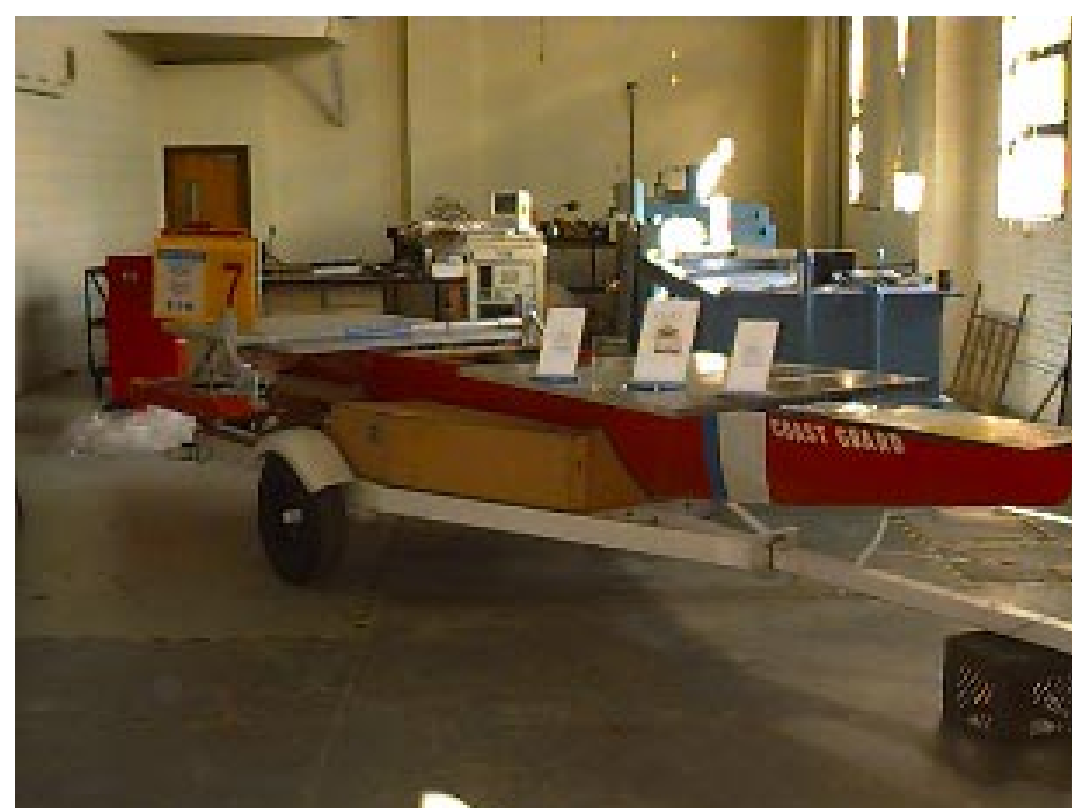

Figure 1: The USCGA 1996 Solar Splash Entry (on trailer)

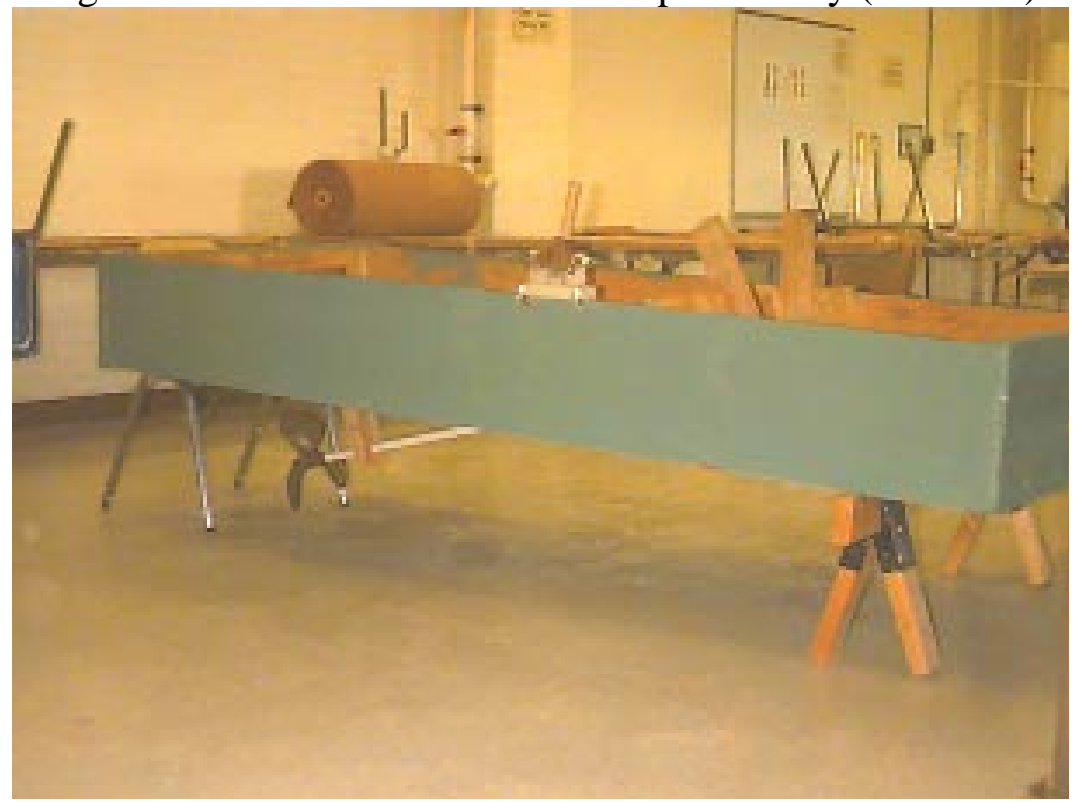

Figure 2: The Propulsion Test Barge

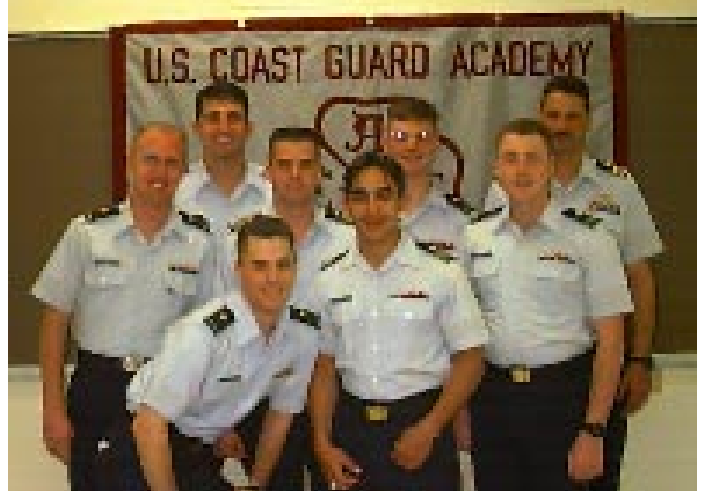

Figure 3: The 1996 USCGA Design Team

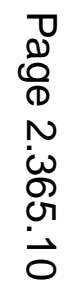

